\title{
Popular Views of Old Age in America, 1900-1950
}

\author{
Laura Davidow Hirshbein, $M D, P h D$
}

The aging of the American population has significantly changed medical practice over the last century. As is well known, life expectancy first began to increase dramatically in the late 19th century, but at the same time that the numbers of older people have been increasing, the social and cultural meanings of growing old have also changed. It is likely that different cohorts of older people have had different experiences with old age because of the time periods they lived through. This paper offers one way to look at some of the historical changes that have affected the public and the medical profession on the subject of old age by looking at old age through American popular literature in the first half of the 20th century in three overlapping time periods. In the first three decades of the century, the concept of old age was widely defined, and older people (rather than physicians) were the principal authorities in describing the qualities of old age. In the third and fourth decades of the century, the idea of old age was starting to acquire increasing negative connotations, but chronological age itself did not signal the beginning of old age. However, by the late 1930s and 1940s, old age became widely viewed as a specific social and medical problem to be addressed by professionals, and older people had become a recognizable population, with a variety of groups organized around their care. This paper illustrates changes in American understandings of old age within and without the medical profession and suggests ways in which popular conceptions of old age might continue to shift and affect how physicians take care of their older patients in the future. J Am Geriatr Soc 49:1555-1560, 2001.

Key words: old age; history; United States

$I^{2}$ 1907, the popular magazine Dial published a tribute to the well-known author Edward Everett Hale on his 85th birthday. In this article, Hale's age not only reflected his past worth but also his continuing abilities: "The poet's line, 'Old age hath yet his honor and his toil'-is ex-

From the University of Michigan Hospitals, Ann Arbor, Michigan.

Address correspondence to Laura Davidow Hirshbein, MD, PhD, University of Michigan Hospitals, 900 Wall Street, Ann Arbor, MI 48109. emplified in both of its aspects by Dr. Hale, for the advancing years that have heaped new honors upon his head have also found his shoulders strong to bear new burdens of enterprise and responsibility." ${ }^{1}$ The Dial tribute went on to praise other great men and women, "our octogenarians," who had made significant contributions to the nation because of their long personal histories, and the author boasted that the United States had tremendous resources in the form of older people.

In the first few decades of the 20th century, this article was typical of the popular press coverage on old age. During this time, most of the popular magazine articles that addressed this topic were written by older people and discussed aging in terms of older people's definitions of the later stages of life. However, by the 1940s, popular press reporting of old age had shifted toward accounts of professional interventions into old age. A typical article on old age in 1940s was a spread in Life about a hospital that specialized in the diseases of old age. As the author explained, "Geriatrics, the opposite of pediatrics, is a branch of medicine whose importance is growing with the increase in the U.S. old-age population." ${ }^{2}$ By this time, old age within popular literature had become a topic for medical and other professional intervention, rather than a way to explain people's lives or their position in the national order.

Old age appears to be a biologically determined stage of life. Humans have always grown older, although human life expectancy has certainly increased in the past century. Nevertheless, although the biological features of aging are reasonably predictable, the meaning of old age for anyone in society is anything but a given. In addition, older people have lived through a number of historical times that have helped to shape how they view getting older. One way of tracing changes in older persons' views of old age over time is by reviewing popular literature. Popular literature is a good source to examine public opinion, because, in the 20th century, Americans have had unprecedented access to mass-produced cultural products, with increases in national publications, improved book circulation, the expansion of advertising, and other forms of media, particularly motion pictures..$^{3-6}$ The idea of old age in American popular culture has substantially changed over the last century, and this change indicates that there will likely be further changes.

Old age in the first half of the 20th century is particularly important to explore because, as most historians agree, 
there were significant changes in ideas about old age during that time..$^{7-9}$ In addition, there have been tremendous changes over time in the cultural meanings of old age. ${ }^{10}$ This paper surveys popular representations of old age between 1900 and 1950 by looking at the magazines of mass consumption during that time. All magazines articles on the topics of old age and longevity were surveyed for ideas and information about old age and the location of authority on this topic. The article citations were located through the Reader's Guide to Periodical Literature,$^{11}$ the index to all popularly written articles since the late 19th century. The articles cited in this paper are representative of the larger number of articles on this topic.

Changes in ideas about old age in the popular press occurred gradually in the early 20th century in three overlapping phases. In the first phase, between 1900 and 1920, many of the popular magazine articles that addressed old age were written by or about older people and their lives (rather than about physicians or medical interventions into old age). The idea of old age within these articles was not fixed but rather was dictated by the experiences of older people. In addition, older people's memories of the past constituted an important element of popular discussions about old age. In the second phase, between 1920 and the early 1930 s, there was a shift toward a more negative reporting of the effects of old age. However, at the same time, individuals were also free to try to extend their lives and did not necessarily become old just because of advancing chronological age. In addition, memories of the past were still an important component of ideas about old age, although those memories were seen as less valuable in modern society. In the third phase, which started in the 1930s and gained momentum by the end of World War II, popular press reporting of old age shifted toward accounts of professional interventions into old age. Physicians became the primary authorities on aging, and older people were not specifically connected to their memories of the past but instead became patients with histories structured by medical needs and interventions.

\section{0-1920}

Over the last century, physicians have told the history of old age in terms of physician interventions into the later stage of life, ${ }^{12,13}$ but physicians did not begin to gain significant popular authority in general until the early 20th century ${ }^{14}$ and did not begin to dominate public opinion on the topic of old age until the 1930s and 1940s. In the late 19th and early 20th centuries, most people looked to popular sources for information about health and illness, ${ }^{15}$ and older people themselves were considered the most important sources of information about growing old, staying healthy, and prolonging life. These older people did not form a self-conscious group or an identifiable population, nor was there a specific age at which someone might be considered old. However, to the extent that anyone looked to experts on the subject of old age, older people served in this role.

In the first decades of the 20th century, older people wrote and were interviewed in popular magazines about their experiences of staying healthy and approaching old age. These older authors and subjects were from elite classes in society and were by no means a representative sample of all older Americans. Still, these representations dominated the popular literature during this time. Older people identified no age cutoff or set of physical or mental attributes that characterized old age. Some even denied the label of old and instead emphasized that the later years of life were shaped by their many years of experience. ${ }^{16,17}$ One writer said that "To be old is to be born again. It is another life, motivated more by love than hate, more by self-effacement than by ambition, more by catholic charity than by headlong zeal." 18 Others agreed that old age was certainly different from youth and that there were appropriate behaviors and attitudes for older people. ${ }^{19-21}$ For many of these writers, there was a proper way to grow old and to stay mentally and physically healthy, but there were no negative features necessarily associated with old age.

Although there were some who described disability in old age during this time, most of the older people who wrote or were interviewed emphasized their strengths as older people and the beauties of old age. ${ }^{22,23}$ One older woman argued that older people "have more sense and more discrimination and a clearer perception of what true enjoyment consists in." 24 Writers who identified themselves as advanced in years, and those interviewed by journalists because of their ages, created an image of an old age to which others could relate because of common experiences and priorities, rather than any specific physical characteristics. Writers who did identify specific ailments connected to old age emphasized that it was possible to entirely avoid these negative consequences of the aging process. Some cautioned against the perils of an infirm body or mind, and argued that the best way to avoid these was to "Think youth and health, instead of old age and decay." 25 Others emphasized the importance of avoiding limitations or restrictions just because of age. ${ }^{26-28}$ Some older figures became well known for their individual prescriptions for healthful longevity. Admiral George Dewey, a Civil War veteran and hero of the Spanish-American War, ${ }^{29}$ made his own health decisions and acted accordingly, and became famous for his refusal to attend banquets or funerals for fear that they would shorten his life. ${ }^{30,31}$

Although health professionals offered advice in this time period ${ }^{32-35}$ and one physician (I.L. Nascher) in 1909 even suggested a medical specialty devoted to old age, ${ }^{36}$ commentators within the popular literature were ready and able to adapt medical and scientific viewpoints to their own purposes. If physicians discussed limitations in old age, popular commentators rejected their advice. Instead, authors within the popular literature embraced promises to extend life, with or without professional help. For example, some older individuals were interviewed on their ability to sustain their activities in old age, and many pointed out their successes in spite of their physicians' pronouncements about their health or abilities. Although many admitted to seeking advice from their physicians, they also often described the errors that their physicians made in advocating too much restriction in areas such as diet and activity..$^{37-39}$ One veteran of the Civil War consulted his physician about the advisability of exercise and received advice that he did not like. So, in spite of his physician's disapproval, this veteran carried on his program by himself and presented his new good health to his physician's amazement 2 years later. ${ }^{40}$ Many of the older indi- 
viduals who wrote and were interviewed at this time made references to their own good health and frequently commented that, although physicians did not hesitate to give advice, physicians in general were ignorant, misinformed, and too pessimistic about abilities in advancing years.

Not only were older people the most authoritative figures within the popular literature on the topic of growing older, but also the idea of old age had a broader cultural meaning because older people represented the past. As one historian has pointed out, the memory of the past was important in the late 19th and early 20th centuries as Americans constructed new traditions for themselves and reinvented a patriotism of a new America (in contrast to weakening European states). ${ }^{41}$ During this time, writers in the popular press illustrated the relationship between old age and history; old age was identified as a time when people had memories of the past, and older people symbolized the past. In addition, older people represented the role of tradition in American culture. Older writers shared their memories with early-20th-century reading audiences with the idea that recollections of the past would be important in shaping modern American society. According to some commentators, older people could provide instruction in the history of the nation and in some ways were better sources of information than books. ${ }^{42-44}$ Representations of old age by and about aging people at this time generally included some reference to memory, and remembrance of the past linked together people of varying ages who insisted that the nation needed to look to the past and the future.

Memory of the past, as shared by older figures in society, could also be important in helping interpret present events. The memories of Civil War veterans helped to shape Americans' experiences at the beginning of World War I. ${ }^{45}$ Not only did older men's memories of war help to frame contemporary experience, but also older men could symbolize past heroism and self-sacrifice. In Civil War reenactments in the 1910s, as one historian has described, the veterans of the war played a particular role by reminding the public, through their clothes and their marks of age, of the personal aspects of the war. ${ }^{46}$ During the first two decades of the 20th century, when Americans were still adjusting to the transitions from 19th-century culture, older people symbolized the previous era, which people saw in retrospect as stable and heroic. Whether or not these images of older people corresponded to real culture or events from the 19th century, they seemed to embody the memories that people in the 20th century wanted to have about the past.

\section{0-EARLY 1930S}

In the years after World War I, popular ideas about old age and the value of older people's memories about the past underwent a significant shift. Although many writers before the 1920s had encouraged older people to engage in activities that would prolong youth and postpone decay, this advice became more important in the following decades as images of decrepitude in old age became more common. However, although old age itself seemed more unpleasant, it was not inevitable within the popular literature. Older people, who remained the most important authorities on old age, proclaimed that chronological age was not the way to understand someone's real age. Instead, old age as a category included those who did not work to keep themselves young, and people who were advanced in years explained their efforts to look and act younger. At the same time that older people talked about avoiding what they understood as old age, popular ideas about the past and the present revealed a diminished role for older people's memory and the tradition it symbolized. As Americans became aware of their nation's position as a new national power in the 1920s, many encouraged a look to the future rather than the past.

In the 1910s and 1920s, there were numerous products and services that were directed toward people with the goal of avoiding decay in old age. One example of the opportunity for people to extend their lives was the 1914 founding of the Life Extension Institute (LEI), an organization formed to assist businessmen and some workingclass men in prolonging their lives and postponing old age. ${ }^{47}$ The LEI was a product of business concerns and had strong ties to the life insurance industry. The LEI offered men of all ages an opportunity to extend their lives by following some simple health precepts. The major health efforts of the LEI were directed toward encouraging men to have annual physical examinations to detect early disease and promote health maintenance practices. Although this may seem commonplace today, the LEI was advocating examinations in health during a time when few physicians routinely saw patients outside of episodes of illness. ${ }^{48}$

Another type of opportunity available primarily to men was the possibility of surgical rejuvenation. ${ }^{49}$ Several surgeons and endocrinologists in the 1920s, notably Eugen Steinach and Harry Benjamin, claimed to be able to reverse the characteristics of aging in men and renew men's vigor and vitality through a simple vasectomy. In the course of selling their surgical procedures, these rejuvenators explicitly described the negative consequences of old age in both men and laboratory rats, and contrasted old age with the rejuvenating effects of their operation. Through the methods advocated by the rejuvenators, whose science was accepted at the time, ${ }^{50-53}$ older men could indefinitely maintain youthful vigor and prowess in business or sex and avoid breakdown. Although the orthodox wing of the medical profession ultimately condemned these practitioners ${ }^{54}$ discussions of rejuvenation permeated the popular literature in the 1920s.

Although older people, along with everyone else in the population, had the possibility of staying young in spirit and in physical condition, there remained a relationship between older people and memory in the years after World War I. However, although older people were still acknowledged to have a unique perspective on the past, their ability to remember did not help them in a postwar society that increasingly celebrated looking forward. The older soldiers' pastoral interpretations of war derived from the memories of their Civil War experiences had been shattered by the young soldiers' descriptions of the brutality of World War I. In addition, changes in the tempo of society and increasing technical innovation made reminiscences of 19 th-century times irrelevant. By the 1920 s, social commentators increasingly advocated looking toward the future instead of remembering the past by heeding the wisdom of America's older people. ${ }^{55}$ 
Although popular discussions of old age in the 1920s and early 1930s deemphasized the value of older people's memories, those memories still served an important stabilizing function in the turmoil of the $1920 \mathrm{~s} .{ }^{56,57}$ In addition, the contrast between America's younger and older generations in the 1920s helped commentators to make sense of changes in national identity and America's role as a world power after World War I. ${ }^{58}$ However, at the same time that older people's memories of the past were grouped together as representative of the time gone by, old age began to be seen less as an individual stage and more as a population phenomenon. In the 1930s and 1940s, the grouping of older people as an older population further helped to sever the connection between old age and memory.

\section{LATE 1930S AND BEYOND}

By the 1930s and into the 1940s, national enthusiasm about extending life and avoiding old age was waning. One of the most important causes of this in the 1930s was the continuation of the crushing economic crisis of the Depression. Before the 1930s, older people did not retire because of advanced age ${ }^{59,60}$ and in fact stayed in the workplace until they had sufficient funds to retire. ${ }^{61}$ However, by the early 1930s, especially in the wake of the Depression, retirement in old age was considered essential to help younger workers find jobs. ${ }^{62,63}$ During this time, the increasing numbers of older people came to be seen as adding a burden to American society. As one author wryly pointed out in the Nation in 1935, "Doctors will have to be warned to cease their pernicious efforts to lengthen the span of human life, and some provision will have to be made for disposing of those persons who persist in living on in a society which is finding less and less work for older men." ${ }^{64}$ By 1935, when Social Security was enacted, old people as a specific group requiring economic intervention was firmly established.

At the same time that Americans were beginning to see old age in terms of a population of people with economic needs, a number of professional groups were beginning to take an interest in old age. Although physicians had been writing about old age since the 19th century, they did not become acknowledged experts on this topic within popular literature until the 1930s and 1940s. A variety of scientists, who identified themselves as working in gerontology, began serious inquiries into the problems of old age at this time. ${ }^{65}$ In addition, other professional groups became interested in old age as a social problem. Social workers, for example, became vocal about the plight of older people and the possibilities for social work assistance for them by the 1930s. ${ }^{66,67}$ In the 1940s, government agencies, such as the U.S. Public Health Service's National Advisory Committee on Gerontology, began to explore old age. ${ }^{68,69}$ By 1950, old age was seen as an economic, social, and medical problem that demanded management by a variety of professional groups.

One of the groups that became increasingly successful as it targeted old age as a topic for professional intervention was psychology. As early as the 1920s, G. Stanley Hall $^{70,71}$ and Lillian Martin, ${ }^{72,73}$ two psychologists who wrote from their authority both as older people and as professionals within the discipline, advocated moving the study of normal psychology toward the end of life. During the 1930s, a number of psychologists began to expand their work on childhood psychology to encompass old age. ${ }^{74,75}$ However, although these psychologists were intent on defining what was normal for older people, they determined normal ability for older people by comparing them with children and young adults. In their tests and in their conclusions, psychologists used children as an ideal. In comparison, the abilities of older people seemed inferior. ${ }^{76}$ In their portrait of a life trajectory of measurable qualities, psychologists showed that individuals peaked in childhood and declined in old age. ${ }^{77,78}$ Although psychologists were genuinely trying to expand scientific knowledge regarding old age, their bias toward children may have helped to further the growing idea that old age meant degeneration and declining ability. ${ }^{79-81}$

As with psychology, the growing medical interest in old age may have unintentionally helped advance the idea that old age is accompanied by inevitable pathology. The national presence of a medical specialty devoted to old age came about with the 1942 formation of the American Geriatrics Society. ${ }^{82}$ Geriatricians attempted to differentiate normal and abnormal aging, and define appropriate professional intervention. In the process, although they were not successful in maintaining as their domain all of the medical problems of old age that they initially claimed for their specialty, they did succeed in alerting the medical profession to some of the unique rewards and challenges of treating older people. ${ }^{83,84}$ However, although they were often supportive of the problems of older people, the language of geriatricians' interventions emphasized the disease and disability that were inevitable products of growing old. In addition, increasing physician interest in old age meant a decline in older people's authority to explain the nature of old age.

As psychologists and geriatricians addressed the problems of old age, they argued that they were doing something to alleviate a national problem. During the 1930s and 1940s, the relationship of older people to national memory shifted. In the early decades of the 20th century, older people represented the past. However, by the late 1940s, older people represented a population that was a national problem awaiting a solution. When older people became subjects and patients of professional intervention, their personal or collective memories of the past became subsumed under a medical model. Instead of discussing the memories of older people and their meanings for Americans, the national focus became the numbers of older people and the challenge those numbers presented to the increasing number of experts in American society. ${ }^{85,86}$

\section{CONCLUSION}

It is clear that public and professional attention to old age increased over the first half of the 20th century. Most explanations for this have been linked to increasing numbers of older people in this nation over the last century. The numbers of older people have certainly been growing; in 1900 the population age 65 and older was 3.1 million (4.1\% of the total population), in 1950 it was 12.2 million $(8.1 \%$ of the total), and in 1997 it was 34 million $(12.7 \%$ of the total). ${ }^{87,88}$ However, although the numbers are compelling, what I find more interesting are the ways in which public commentators derived meaning from the increase in 
the numbers of older people, projected values onto the later years of life, and redefined old age as a category that matched certain people with certain social and moral characteristics. ${ }^{89}$ The changes in popular ideas about old age over time indicate that popular understandings of old age will likely change in the future. In addition, different cohorts of older people will likely have different assumptions about and expectations for old age. We will provide better patient care if we can be attuned to how our patients view old age and stay aware of the information they are exposed to (e.g., the popular media, drug company advertisements, information from alternative healthcare sources, and information from senior citizen advocacy groups) outside their interactions with the healthcare system.

As we continue to make professional interventions into old age, we need to keep in mind that the idea of growing old has not only biological implications but also social and cultural ones. It has not been inevitable that people retire at age 65 , nor is it inevitable that older people look to physicians for authority on the process of growing older. The change in popular ideas about old age over the first half of the 20th century reveals that there are tremendous variations in how people see old age, its physical and mental attributes, and its relationship to personal and national memory. With the change that has already occurred, it is reasonable to suppose that further change can and will occur. In addition, it is important to note the distance that has sometimes existed between popular and medical ideas of old age.

Physicians' relationships with older people will likely further change as different cohorts, such as the baby boomers, grow older. We should be aware of different generations' possibly different expectations about things such as diet, exercise, physical activity, sex, appropriate leisure activities, financial status, and relationships to medical professionals. In addition, what other sources of authority about old age will develop among future generations of older people? We have seen varying levels of religious and ethnic identifications over the century, but these seem to be shifting with different generations. We also have had explosions of new technology that make prolongation of life possible, but sometimes at a terrible cost. What choices will future generations of older people make about the quality and quantity of their lives? Changes in old age have certainly taken place in the past. For the future, it will be important to stay attuned to patients' expectations and the cultural meanings of old age to better serve the population of old people at any given moment in time.

\section{REFERENCES}

1. Our octogenarians. Dial, 16 April 1907;42:241-242.

2. Geriatrics: Welfare hospital specializes in oldsters' chronic diseases. Life, 7 October 1940;9:45-48.

3. Sklar R. Movie-Made America: A Cultural History of American Movies New York: Vintage Books, 1994.

4. Rubin JS. Between culture and consumption: The mediation of the middlebrow. In: Fox RW, Lears TJJ, eds. The Power of Culture: Critical Essays in American History. Chicago: University of Chicago Press, 1993 pp 163-191.

5. Marchand R. Advertising the American Dream: Making Way for Modernity, 1920-1940. Berkeley: University of California Press, 1985.

6. Lears J. Fables of Abundance: A Cultural History of Advertising in America. New York: Basic Books, 1994.

7. Haber C. Beyond Sixty-Five: The Dilemma of Old Age in America's Past. New York: Cambridge University Press, 1983.
8. Fischer DH. Growing Old in America. New York: Oxford University Press, 1978.

9. Achenbaum WA. Old Age in the New Land: The American Experience Since 1790. Baltimore: The Johns Hopkins University Press, 1978.

10. Cole TR. The Journey of Life: A Cultural History of Aging in America. New York: Cambridge University Press, 1992.

11. Reader's Guide to Periodical Literature, Volumes 1900 to 1999 . New York: H.W. Wilson, Co., 1904-1999.

12. Freeman JT. Aging: Its History and Literature. New York: Human Sciences Press, 1979.

13. Nascher IL. A history of geriatrics. Med Rev Rev 1926;32:281-284.

14. Starr P. The Social Transformation of American Medicine. New York: Basic Books, 1982.

15. Fellman AC, Fellman M. Making Sense of Self: Medical Advice Literature in Late Nineteenth-Century America. Philadelphia: University of Pennsylvania Press, 1981.

16. Knight W. De senectute. Living Age, 23 December 1905;247:747-757.

17. Powell EP. An idyl for old folk. Independent, 14 March 1912;72:572-575.

18. Taylor EG. The best years. Reader Magazine, December 1906;9:67.

19. How to Grow Old. Nation, 1 November 1906;83:365.

20. Mabie H. Occupation for aged people. Outlook, 16 December 1899;63:913.

21. Bruere MB. Growing old together. Good Housekeeping, January 1914;58: 86-92.

22. Edwards LB. Fulfillment. Harper's Monthly, September 1905;111:587.

23. Garrison T. Maturity. Cosmopolitan, December 1904;38:168.

24. Hawthorne H. When are we old? Delineator, November 1917;91:29.

25. Holmes I. The international live forever club. New England Magazine, November 1907;37:383.

26. The autobiography of an elderly woman. Everybody's Magazine, May 1906; 14:625-630.

27. Butler EP. Young Bob Kemp. Harper's Monthly, September 1905;111: 527-534.

28. Francis C. Young at seventy. Review of Reviews, April 1918;57:415-416.

29. Braisted WR. George Dewey (1837-1917). In: Spiller J, ed. Dictionary of American Military Biography, Volume I. Westport, CT: Greenwood Press, 1984, pp 260-263.

30. How Admiral Dewey keeps his grip at the age of seventy-eight. Current Opinion, November 1916;61:314.

31. Kelly FC. Why Admiral Dewey is well at 78. American Magazine, September 1916;82:50.

32. Exercise for the aged. Current Literature, January 1905;38:72.

33. To tell age by the skin. Literary Digest, 31 July 1920;66:21-22.

34. Carson G. Cornflake Crusade. New York: Rinehart, 1957.

35. Christison JS. Science and immortality. North American Review, June 1905; 180:842.

36. Nascher IL. Geriatrics: The Diseases of Old Age and Their Treatment. Philadelphia: P. Blakiston's Son \& Co., 1914.

37. The sunny side of being one hundred. Literary Digest, 29 July 1922;74:38-42.

38. Farquhar AB. Life gets to be more fun every day. Collier's, 17 February 1923;71:7-8

39. Catt CC. The years I like best. Good Housekeeping, October 1923;77. 17,181-184.

40. Beasley NB. A physical marvel at 73. American Magazine, December 1917; 84:53-54.

41. Kammen M. Mystic Cords of Memory: The Transformation of Tradition in American Culture. New York: Vintage Books, 1991.

42. Sangster ME. Life's afternoon: A talk with old ladies. Ladies' Home Journal, January 1900;17:22.

43. Jessopp A. The elders of Arcady. Nineteenth Century, May 1900;47:776-792.

44. Gilchrist BB. About old ladies. New England Magazine, March 1908;38: 118-122.

45. Kennedy DM. Over Here: The First World War and American Society. New York: Oxford University Press, 1980.

46. Glassberg D. American Historical Pageantry: The Uses of Tradition in the Early Twentieth Century. Chapel Hill: University of North Carolina Press, 1990.

47. Hirshbein LD. Masculinity, work, and the fountain of youth: Irving Fisher and the Life Extension Institute, 1914-1931. Can Bull Med Hist 1999;16: 89-124.

48. Martin SC, Howell JD. One hundred years of clinical preventive medicine in America. Primary Care 1989;16:3-8.

49. Hirshbein LD. The glandular solution: Sex, masculinity, and aging in the 1920s. J Hist Sexuality 2000;9:277-304.

50. Lydston G. Sex gland implantation: Additional cases and conclusions to date. JAMA 1916;66:1540-1543.

51. Wolbarst AL. A report on the Steinach operation in senility and premature senility. NY Med J 1922;115:543-545. 
52. Sengoopta C. Rejuvenation and the prolongation of life: Science or quackery? Perspect Biol Med 1993;37:55-66.

53. Hall DL. Biology, sex hormones and sexism in the 1920's. Philosophical Forum 1973-74;5:87-89.

54. Jahiel J. Rejuvenation research and the American Medical Association in the early twentieth century: Paradigms in conflict. PhD dissertation, Boston University, 1992.

55. May H. The End of American Innocence: A Study of the First Years of Our Own Time, 1912-1917. New York: Alfred A. Knopf, 1959.

56. Comstock S. The peppermint years. Harper's Monthly, July 1929;159:180-188

57. Ernle. The revolt of youth. Nineteenth Century and After, December 1920; 88:925-934.

58. Hirshbein LD. The flapper and the fogy: Representations of gender and age in the 1920s. J Fam Hist 2001;26:112-137.

59. Graebner W. A History of Retirement: The Meaning and Function of an American Institution, 1885-1978. New Haven, CT: Yale University Press, 1980.

60. Carter SB, Sutch R. Myth of the industrial scrap heap: A revisionist view of turn-of-the-century American retirement. J Econom Hist 1996;56:5-38.

61. Gratton B. Urban Elders: Family, Work and Welfare Among Boston's Aged, 1890-1950. Philadelphia: Temple University Press, 1985.

62. Lubove R. The Struggle for Social Security, 1900-1935. Pittsburgh: University of Pittsburgh Press, 1968.

63. Berkowitz E, McQuaid K. Social security and the American welfare state. Res Econom Hist 1991;6[Suppl.]:169-90.

64. A modest proposal. Nation, 10 April 1935;140:406.

65. Achenbaum WA. Crossing Frontiers: Gerontology Emerges as a Science. New York: Cambridge University Press, 1995.

66. Morgan CM. What makes old folks happy. Survey, December 1935;71: 360-361.

67. Lubove R. The Professional Altruist: The Emergence of Social Work as a Career, 1880-1930. New York: Atheneum, 1965.

68. Attack on old age problems launched by health service. Science News Letter, 7 December 1940;38:356.

69. Cowdry EV. Problems of Ageing: Biological and Medical Aspects. Baltimore: Williams \& Wilkins Company, 1942.
70. Hall GS. Senescence: The Last Half of Life. New York: Appleton and Company, 1922.

71. Hall GS. Old age. Atlantic Monthly, January 1921;127:23-31.

72. Martin LJ, de Gruchy C. Salvaging Old Age. New York: Macmillan Company, 1930.

73. Martin LJ. Old age-life's harvest time. Ladies' Home Journal 1931;48:112.

74. Miles WR. Measures of certain human abilities throughout the lifespan. Proc National Acad Sci 1931;17:627-633.

75. Ruch FL. The differentiative effects of age upon human learning. J Gen Psychol 1934;11:261-262.

76. Miles CC, Miles WR. The correlation of intelligence scores and chronological age from early to late maturity. Am J Psychol 1932;44:44-78.

77. Gilbert JG. Mental efficiency in senescence. Arch Psychol 1935;27:12-16.

78. Miles WR. Age and human ability. Psychological Rev 1933;40:114-115.

79. Bird C. As we grow old. Science Digest, December 1940;8:23-27.

80. Psychological age of the old. Science 1931;73[Suppl];12,14.

81. Lawton G, ed. New Goals for Old Age. New York: Columbia University Press, 1943.

82. Hirshbein LD. 'Normal' aging, senility, and the American Geriatrics Society in the 1940s. J Hist Med Allied Sci 2000;55:337-362.

83. Spicker SF, Woodward KM, Van Tassel DD, eds. Aging and the Elderly: Humanistic Perspectives in Gerontology. Atlantic Highlands, NJ: Humanities Press, Inc., 1978.

84. Van Tassel D, Stearns PN, eds. Old Age in a Bureaucratic Society: The Elderly, the Experts, and the State in American History. New York: Greenwood Press, 1986.

85. Cowdry EV. Problems of Ageing: Biological and Medical Aspects. Baltimore: Williams \& Wilkins Company, 1942.

86. Cowdry EV. We grow old. Scientific Monthly 1940;50:51-58.

87. Historical Statistics of the United States: Colonial Times to 1970, Part 1. Washington, DC: Government Printing Office, 1975, p 15.

88. U.S. Bureau of the Census: Statistical Abstract of the United States: 1998, 118th ed. Washington, DC, 1998, p. 16.

89. Hirshbein LD. The transformation of old age: Expertise, gender, and national identity, 1900-1950. PhD dissertation, Johns Hopkins University, 2000 